\title{
Kitap Eleștirisi
}

\section{Șerife Öztürk}

Ankara Üniversitesi Sosyal Bilimler Enstitüsü

serife.ozturk06@hotmail.com

\section{7/24. Geç Kapitalizm ve Uykuların Sonu}

Orijinal Adı: 7/24. Late Capitalism and The Ends of Sleep

Jonathan Crary

Çeviren: Nedim Çatlı

İstanbul: Metis Yayınları, 2015, 125 sayfa.

Sanat tarihi profesörü olan Jonathan Crary; Edward Said, Meyer Schapiro, F.W. Dupee ve Lucien Goldmann gibi isimlerin öğrencisidir. Crary, Columbia, Princeton ve Harvard üniversitelerinde çalışmalarını sürdürmektedir. Kurucularından olduğu Zone Books'ta (1986) editörlüğe devam eden Crary'nin, çağdaş sanat ve kültür üzerine pek çok eleştiri yazısı bulunmaktadır. Suspensions of Perception: Attention, Spectacle and Modern Culture (1999, Algının Askıya Alınması: Dikkat, Gösteri ve Modern Kültür) en bilinen kitaplarındandır. Türkçe'de ise Gözlemcinin Teknikleri: On Dokuzuncu Yüzyılda Görme ve Modernite (1990; 2004) ile tanınmaktadır. 
Crary'nin kitapları arasında en dikkat çekici olanı, Gözlemcinin Teknikleri: On Dokuzuncu Yüzyılda Görme ve Modernite' dir. Görsel kültür kuramcısı olması nedeniyle Crary bu kitabında modern görsel kültürün kökenlerini incelemiştir. Diğer bir kitabı olan Algının Askıya Alınması: Dikkat, Gösteri ve Modern Kültür'de ise 1880-1905 yılları arasında endüstrileşmenin yeni başlamasıyla birlikte ortaya çıkan aşırı duyusal yüklemeye maruz kalmış toplumu araştırmış ve dikkatlerin bu dönemle birlikte dağılmaya başladı̆̆ını vurgulamıştır.

Crary, kitaplarındaki tüketim kültürü, boş zaman ve popüler kültürü değerlendirmesiyle Kültürel Çalışmaların izlerini taşımakta, kapitalizme bakış açısıyla da ekonomi politiğe eleştirel yaklaşımını gözler önüne sermektedir.

Crary, önceki iki kitabında teknolojinin kapitalizm için yeni kapılar açtığını, dönemsel farklılıklar üzerinde durarak belirtmiştir. 7/24: Geç Kapitalizm ve Uykuların Sonu da öncekiler gibi gösteri kültürü üzerine yazılan yazarın belki de en önemli kitabı. Teknolojinin getirdiklerini gözler önüne sererken verdiği örnekler ilginç ve akılda kalıcı. Crary'nin diğer iki kitabı gibi, teknolojiye yaptığı vurgu, yeni medya ortamlarının insanların yaşam alanındaki yerlerini düşündürmektedir. Kitap, konusu ve üzerinde durduğu hususlar itibariyle Crary'nin önceki kitaplarının devamı niteliğindedir.

Dört kısa bölümden oluşan kitapta açık ve anlaşılır bir dil kullanılmıştır. Polemikçi bir üslupla kaleme alınan kitapta, teknolojinin olanaklarına karşın uyku üzerindeki tahribatı ve bu konudaki çalışmalar tartışlmaktadır. Kitap, özellikle teknolojik gelişmelere, uyku araştırmalarına meraklı okuyucu kitlesine hitap etmekte, tüketiciyi uyutmama çabaları ve uyku üzerine oynanan oyunlar hakkında bilgi vermektedir.

Küresel şirketler, teknoloji aracılığıyla, insanları birer meta haline getirmekte ve bu durumu sekteye uğratmamak için de birtakım çabalar içine girmektedirler. Bu çabalardan biri de uyutmama/az uyutma çabasıdır. Kapitalistler, tüketicinin çeşitli yöntemlerle uyanık kalmasını sağlamak, onları tüketime yönlendirmek böylece daha çok para kazanmanın yollarını araştırmaktadırlar.

Toplumsal ilişkilerin bütünlüğü ya da uyuma hakkındaki birtakım temel varsayımların uyku meselesi etrafında toplandığının anlatıldığı kitapta, uykunun hayati önem taşıdığı ve zamanla kapitalistlerin para kazanma uğruna nasıl sürekli erozyona uğratıldığı okuyucuya aktarılmaktadır. 
Crary kitabında her yeni teknolojiyle birlikte insanların özgürlük alanının daha da genişlediğinin zannedildiği ama durumun hiç de öyle olmadığı, sürekli ve çok daha sıkı bir gözetimin gerçekleştiği üzerinde durmaktadır.

Kitabın birinci bölümünün ilk satırları çarpıcı bir örnekle başlamaktadır. ABD Savunma Bakanlığı'nın uykusuz, 7/24 savaşan asker projesini anlatarak Bakanlığın beyaz taçlı serçelerin göç mevsiminde yedi gün boyunca uyumadan yol almalarından hareketle, bilim adamlarının bu durumu insanlar, özellikle askerler üzerinde uygulama planlarından bahsedilmektedir. Bilim ve ordunun işbirliği içerisinde olduğu bu projede amaç Crary'ye göre, idrak arttırma biçimlerini geliştirmek ve uykusuz asker, uykusuz işçi, uykusuz tüketici yaratmak. ${ }^{1}$

Kitabın yine ilk bölümünde, Crary'nin insanları uyutmama çabası yönündeki çalışmalara verdiği başka bir örnek de yer almaktadır. Rus/ Avrupa uzay konsorsiyumunun "gece boyunca gün 1şı̆̆1" sloganıyla 24 saat gün 1şı̆̆ından yararlanılacak bir projenin hazırlandığının, amacın sürekli gün 1şı̆̆ıyla $7 / 24$ çalışmak, üretmek ve tüketmek olduğunun kaydedildiği kitapta, bu projeye uyku dâhil çeşitli metabolizma düzenlerini sekteye uğratacağı, insanlar ve hayvanlar için zarar verici boyutta olacağından itirazlar geldiğinin altı çizilmektedir. Uykunun önemini vurgulamak için çok çarpıcı bir örnek vermektedir Crary: Guantanamo'daki esir kampında esirler, uykudan yoksun bırakılarak işkenceye maruz birakılmaktadır. ${ }^{2}$

7/24'ün bir farksızlık zamanı olarak tanımlandığ1 kitapta, 20. yüzyıl boyunca uyku zamanının kısaldığı, artık insanların daha çok tüketime yönlendirilmesi için az uyutulma çabasına maruz bırakıldığı belirtilerek, "uyku erozyonu" kavramı kullanılmaktadır. ${ }^{3}$

Sermaye sahipleri, tüketicileri uyutmama çabasında teknolojiden yararlanmaktadır. Son dönemlerde insanların hayatına girerek neredeyse bir uzvu haline gelen, yaşamlarını ele geçiren yeni medya araçları buna en güzel örnektir. Crary bu durumu şu cümleyle aktarmaktadır: "Mesajlarını ya da kendisine gelen diğer verileri kontrol etmek için gece kendi isteğiyle bir ya da birden fazla kere uyanan insan sayısı katlanarak artmaktadır." 4 "Uyku modu" kavramının altında yatan anlamı kaç kişi düşünmüştür? Bu kitabı okuduktan sonra herkesin aklında kalacak birkaç kavramdan biri belki de budur. Bu kavramla birlikte, hiçbir şeyin asla tamamen kapalı olmadığı ve hiçbir zaman tam anlamıyla istirahat durumunun bulunmadığı bir kez daha akla gelmektedir.

Crary kitabında, "insan varoluşunun içine sızılarak ele geçirilmemiş zamanı çok azdır artık" ${ }^{5}$ diyerek, yeni medya araçlarını işaret etmektedir. Yeni medya 
ortamlarının yayılım, dijitallik, etkileşim ve kullanıcı türevli içerik ${ }^{6}$ gibi özellikleri nedeniyle, insanlar bilgiye, eğlenceye, alışverişe, oyun vb. ortamlara her yerden kolayca erişim sağlayabilmekte ve 7 / 24 çevrimiçi olabilmektedir. Bu durumu Crary, bir duyu ve hafıza yitimi olarak nitelendirmektedir.

Kitapta "neden uyutmama çabası?" sorusuna Marx referans gösterilerek cevap verilmektedir: "Uyku, kapitalizmin önündeki doğal bariyerlerden sonuncusu." Uykuda geçen her zaman dilimi tüketimin durması ve kapitalistlerin para kazanmaması demektir. Durum böyleyken sermaye sahipleri de uyku süresini azaltmak için kolları sıvamaktadır.

Uykuyla ilgili çalışmaların psikolojikmiş gibi görünüp aslında, her şeyde olduğu gibi, ekonomik temele dayandığı vurgusunu kitap boyunca yapan Crary, insanların uykularına müdahalesiyle uyku ilaçları satışının arttığını, bunun da yine sermaye sahiplerinin işine yaradığının altını çizmektedir. ${ }^{7}$

Kitabın ikinci bölümünde, 7/24 zamansız bir zaman olarak nitelendirilmekte, bu kavramın aynı zamanda içi boş ve soyut olduğuna da vurgu yapılmaktadır. Artık bir kimsenin alışveriş edemeyeceği, tüketemeyeceği veya ağ kaynaklarından yararlanamayacağı hiçbir an, yer ya da durum kalmadığını savunan Crary, Castells' in yeni medya araçlarının hayatımızı çepeçevre sardığını ifade etmek için kullandığı "ağ toplumu"8 kavramını akla getirmektedir.

Teknolojik cihazlardaki arttırılmış gerçeklik üzerinde duran Crary, tıklamak yerine el sallamanın, başla onaylamanın ya da göz kırpmanın komut yerine geçeceği beden hareketlerine dayalı bilgisayar sistemlerinin geliştirildiğini anlatmaktadır. ${ }^{9}$ Crary, bu durumun insanların beden hareketlerinde ve duygusal davranışlarında kısıtlamaya yol açacağını da ima etmektedir.

Kitapta, insanların karar verme süresinin nasıl azaltılacağı, derin derin düşünme ölçüp tartma uğruna heba edilen zamanın nasıl ortadan kaldırılacağı hakkındaki araştırmalara her yıl milyarlarca dolar harcandığına da yer verilmiştir. Bu araştırma bile insanın hafızasını düşünerek güçlendirmek yerine bilinçsizce tüketen bireye dönüştürme isteğinin ispatıdır.

Crary, teknolojik cihazlara sahip olmanın haz ve prestiji de beraberinde getirdiğinin altını çizerek, bu yolla insanların kapitalistlere gönüllü meta olduğunu ifade etmektedir. ${ }^{10}$

Bentham'ın panoptikon (her yeri gören) ${ }^{11}$ kavramina atıfta bulunulan kitapta, teknoloji ile insanların gözetlendiği, kişilerin gönüllü meta olma halleri dışında, gözetleme ve veri madenciliği süreçlerine de katkıda bulunduğu kaydedilmektedir. ${ }^{12}$ 
İnsanların biyolojik ve duygusal olarak normal duygu ve hislerinin uykunun azaltılmasıyla ortaya anormal şekilde çıtı̆̆ı ve bunun da sahte ihtiyaç ve eksiklikler olarak uydurulduğunu ifade eden Crary, “Çekingenlik, kayg1, değişken cinsel arzu, dikkat dağınıklığı ya da üzüntü nosyonlarıyla ortaya konan insan duygulanımı ve duygusunun dalgalı dokuları yanlış biçimde, kar getiren ilaçların hedefindeki tıbbi rahatsızlıklara dönüştürülüyor"13 demektedir.

Çalışma ve boş zaman arasındaki sınırın ortadan kalktığı üzerinde durulan bölümde, çevrimiçi karşılığı olmayan gerçek hayat faaliyetlerinin köreldiği ya da artık önemsizleştiğine vurgu yapılmaktadır.

Marx'ın kapitalizmin tarımla uyumsuz olduğu görüşünü vurgulayarak kitabın üçüncü bölümüne başlayan Crary, tarımın kapitalizmin esas ikametgâhı olamayacağının altını çizmektedir. Bunun nedenini tarım hayatının doğal koşulları olarak ifade eden Crary, kapitalizmin fabrika çiftçiliği modeliyle kendini tarıma dayattığını, bazı şirketlerin genetiğiyle oynanmış ve patentli tarım malzemeleriyle Marx'ın doğal koşullarını aştıklarını ifade etmektedir. ${ }^{14}$

2. Dünya Savaşı sonrasının yeni iletişim, enformasyon ve bazı paradigmaların biçimlendiği bir dönem olarak nitelendirildiği kitapta, insanların diyaloğuna dayalı panayır, festival ve pazar yerlerinin sosyalleşme mekânı olduğu, onların yerini artık insanların iştahını doyurmaya, tatmin etmeye yönelik faaliyet ve mekânların aldığı belirtilmektedir. ${ }^{15}$ Burada Crary, yine teknolojiyi göz önüne alarak alışveriş merkezleri ve yeni medya ortamlarının insanların sosyal yaşamında değişiklikler yaptığından, insanların artık kendi hazlarının dışında hiçbir şeyle ilgilenmediği ve başkalarıyla diyaloğa girmediği için asosyal hale geldiklerinden bahsetmektedir.

Teknolojiyle birlikte insanların yeni kimliklere büründüğünü belirten, bunu da kendi istekleriyle gerçekleştirdiklerinin vurgusunu yapan yazar, siber uzamın benliği ve dünyayla olan ilişkiyi yeniden icat etme gücüne değinmektedir. ${ }^{16}$

Kitapta dikkatin 7 / 24 zaptedildiğinin altını çizen Crary, elektronik bağlantının sınırsızlık hissi verdiğini aktarmaktadır. Bu hissin yaratılmasında büyük kapitalist şirketlerden olan Google ve Facebook'un katkısına değinerek, bu şirketlerin hedeflerinden birinin sürekli arayüz fikrini normalleştirmek olduğunu yazmaktadır. Kitapta 7/24 kapitalizm içinde insanların bencilleştiğinin de altı çizilmektedir. ${ }^{17}$

Dördüncü ve son bölümde ilk olarak rüya gören denekler üzerinde yapılan bir araştırmadan bahsedilerek, beyin taramalarından alınan verilerin, dijital görüntüler elde etmek için kullanıldığı anlatılmaktadır. Dijital iletişimin bireysel 
ve toplumsal hayatı metalaştırdığı belirtilerek bundan kaçışın olmadığı belirtilmektedir. ${ }^{18}$

Uykunun bireyleşmeden periyodik bir kurtuluş olduğunu savunan Crary uykuyu, kişinin gündüz yaşayıp yönettiği sı̆̆ öznelliklerin gevşek atılmış düğümlerinin geceleri çözülmesi şeklinde tanımlamaktadır. ${ }^{19}$

Kitabı okurken uykunun belki hiç düşünülmeyen ve farklı bir özelliği akla gelmektedir: İnsanları özgürleştirmesi. Yazar, uykunun bu özelliğini kitabında açıkça dile getirmemektedir. Ancak insanları uykularına sahip çıkmaya davet eden Crary, bunu özgürleşmeleri adına yapmalarını istemektedir.

\section{Notlar}

1 Jonathan Crary, 7/24 Geç Kapitalizm ve Uykularm Sonu, çev. Nedim Çatlı (İstanbul: Metis Yayınları, 2015), 13-15.

2 Crary, $7 / 24,15-18$.

3 Crary, $7 / 24,21$.

4 Crary, $7 / 24,23$.

5 Crary, $7 / 24,24-25$.

6 Mutlu Binark, der., “Yeni Medya Çalışmaları Özel Sayısı Hakkında: Neden?”, Folklor / Edebiyat (2015), 9-18.

7 Crary, 7/24, 27-29.

8 Manuel Castells, "An Introduction to The Information Age", The Information Society içinde, ed. Frank Webster (London: Routledge, 2004), 138-149.

9 Crary, $7 / 24,47$.

10 Crary, 7/24, 49-52.

11 Jeremy Bentham, "Panopticon", The Panopticon Writings içinde, ed. Miran Bozovic (London: Verso, 1995), 29-95.

12 Crary, $7 / 24,54-55$.

13 Crary, 7/24, 60-61.

14 Crary, 7/24, 68-69.

15 Crary, $7 / 24,68$.

16 Crary, 7/24, 76-78.

17 Crary, 7/24, 85-91.

18 Crary, 7/24, 93-100.

19 Crary, 7/24, 122. 